\title{
Modern approaches to managing change in agricultural enterprises
}

\author{
Yulia Shafieva ${ }^{*}, 1$ and Alexandr Maksimenko ${ }^{1}$ \\ ${ }^{1}$ Don State Technical University, Gagarin Square 1, 344003, Rostov-on-Don, Russian Federation
}

\begin{abstract}
The purpose of this study is to develop a model for managing changes in agriculture, based on the use of agricultural engineering tools. Theoretical studies were carried out using the methods of system analysis and generalization of existing scientific developments in the development of agriculture digitalization. As an outcome of the study, the following results were obtained: - the main problems that prevent using of engineering tools to manage changes in domestic agricultural enterprises, were identified; - the main tools of agricultural engineering in the context of changes were identified; - depending on the methods and tools used, a comprehensive engineering model is proposed in order to ensure the management of changes occurring in domestic agricultural enterprises in a crisis environment.
\end{abstract}

\section{Introduction}

Management of changes at any stage of economic development, apart from the cycle phase, is relevant, acquiring special significance in crisis conditions.

At present, the world economy is experiencing unprecedented exogenous shock caused by the spread of a new coronavirus infection $[1,2]$. Most of the previous crises hit humanity at a certain point in time and at the regional level, the COVID-19 pandemic has developed globally, and the radical measures taken by the government of many countries to contain it have caused enormous damage to all sectors of the economy. At the end of 2020, the global forecast defines a 3\% reduction in real GDP, while in developed countries the decline will be $6.1 \%$ [3 -5].

That's why the current conditions for the development of the world economy necessitate the use of a change management approach. Such a change management system, regardless of the industry in which it will be applicable, can only be built on the basis of a computerized complex that includes the appropriate algorithms and engineering instruments.

\section{Methods and materials}

In the course of the study, the following methods were used: categorical analysis, comparative analysis and synthesis.

\footnotetext{
*Corresponding author:julia_shafieva@mail.ru
} 
Categorical analysis was used to identify the content of the "engineering" concept, analysis and synthesis methods were used to integrate theories and concepts, scientific developments on the problems of the agro-industrial complex development.

The study is based on the materials of the national program "Digital Economy of the Russian Federation", materials stated in the articles of Russian and foreign economists, periodicals.

\section{Research results}

The term "engineering" in modern scientific use has appeared relatively recently and is associated with the periods of automation, informatization and following digitalization of countries such as the USA, Italy, France in the late seventies of the twentieth century.

At present, the application of engineering methods for managing changes undergoes not only at the level of an individual economic entity, but also at the level of public policy. A well-defined system for choosing innovative methods for changes management in solving information problems is reflected in the instruments of the domestic budget, tax and customs and tariff policies for 2019-2021. A timely and precise solving of major economic and social problems is determined by changes management performance both at the federal and regional levels [6- 9].

Official government documents have repeatedly substantiated the need to develop and implement a computerized changes management complex. This is relevant not only for knowledge-intensive industries, but also for agriculture, which is a strategic industry with a high export potential and which is switching to a digitalization system, which was previously not typical for this sector of the economy.

The rapid development in the world of information technology has led to the emergence of digital agriculture, based on the system of precision farming, agroinformatization, the use of precise control of agricultural machinery and other instruments [10-13 ].

Digitalization of agriculture, involving the engineering instruments application, is based on the use of various models at all levels of agricultural production management, which include:

- diagnostics of the financial and economic state of enterprises;

- optimization of contractual schemes to minimize costs, reduce tax and credit burden;

- implementation of a management system by responsibility centers and cost centers;

- calculating the break-even point of agricultural enterprises and determining the margin of financial strength;

- monitoring of current activities to organize a system for the agricultural enterprises activities controlling;

- pro forma statement development, taking into account a variety of semantic, stochastic data, both with the use of approximation methods and without their use;

- segment forecasting of the agricultural enterprises activities;

- formation of a system for strategic management of agricultural enterprises;

- management of the bankruptcy procedure, liquidation and reorganization of the agricultural enterprise;

- determination of the level of risk of projects of agricultural organizations;

- determination of the predicted result of innovative projects;

- enterprise management in the context of changes;

- situational-event management of the enterprise;

- management and control by the types of enterprises activities in the agricultural sector in the context of general management, control, formation of a reserve system, pro forma statements, strategic plans, specific objects and processes, and others [14,15] . 
The model of agricultural engineering instruments we proposed is makes it possible to take into account exogenous and endogenous factors in relation to engineering tools for agricultural enterprises, break them down into appropriate management objects and identification features, by combining them into such blocks as: management theory, types and methods of management, approaches (models) of registering facts; characteristics of engineering tools; provision of engineering processes; system of qualimetric indicators.

Within the framework of the proposed model, ten management objects are distinguished in the context of general change management in agricultural enterprises, in particular:

- organization of general management;

- property management of agricultural enterprises;

- risk control;

- management of innovation processes;

- management of financial flows;

- processes of reorganization and liquidation of the enterprise;

- liquidity and solvency management;

- human resource management at agricultural enterprises;

- monitoring and control of the targeted use of subsidies; as well as collateral;

- engineering tools for control organization.

Each object of management is associated with one of six blocks of the model, which include balance theories, information databases; accounting mechanisms and tools, engineering processes for large groups, technology for fixing engineering processes and control.

Thus, a certain engineering method is applied to each control object in accordance with a certain block of the model.

\section{Discussion}

In domestic practice, it is proposed to use about seventy engineering tools, depending on the types of activities of the enterprise; forms of ownership and organizational and legal form; while in modern economic literature there are more than five hundred of them.

The use of engineering tools is of particular importance; when the agricultural enterprise is not liquidated; but continues to operate in difficult economic conditions.

Such a variety of engineering tools and the subsequent problem of their application in a wide variety of fields; taking into account that their approbation is taking place in difficult Russian realities under the influence of changes as in enterprises of traditional industries as well as at the enterprises of the agricultural sector; requires elimination of several basic problems:

- identification and definition of the main factors and functions of the engineering tools application;

- formation of a unified model for the use of engineering tools for agricultural enterprises;

- practical application and implementation of engineering tools in the digitalization of agriculture.

In addition to the abovementioned problems, one should not forget about the fact that the use of engineering tools in the management system of an organization in a changing environment, determination of its strategic development under the influence of various external and internal reasons, are determined by a whole range of factors, such as:

- the emergence of engineering situations;

- formation and compliance with engineering procedures;

- observance of basic economic and balance principles;

- the use of various methods for assessing and calculating the value of the organization; 
- determination of the level of risk of conducting business and implemented processes;

- determination of the financial and economic well-being of the organization and determination of its place in the market;

- possibility of applying and using all available programming languages, automated control systems;

- determination of alternative options for strategic development while forecasting the activities of the organization, etc.

The proposed model of agricultural instruments in the context of changes focuses on ten groups of management objects and the corresponding engineering instruments.

1. Organization of general management of an agricultural enterprise in the context of changes (strategic, predictive, semantic engineering tools).

2. Management and control of the agricultural enterprises property. These engineering tools include organic, substantial, trust, actuarial, discounted and rehabilitated one.

3. Formation of a reserve system for the purpose of management and control, related to agricultural activities, based on hedged and integrated engineering tools.

4. Implementation, application and management of innovative processes in agricultural enterprises. Innovative and venture engineering tools are used for that purpose.

5. Management and control of financial flows and results of agricultural enterprises (surplus ones, client engineering tools).

6. Management of the bankruptcy procedure; reorganization and liquidation of an agricultural enterprise (reorganization; separation; consolidation; liquidation engineering tools).

7. Liquidity management; solvency; determination of the financial position of an agricultural enterprise (monitoring; immunization engineering tools).

8. Human resource management for agricultural enterprises (behavioral; intelligent engineering tools).

9. Management of guarantees; pledges and subsidies intended for the targeted use of agricultural enterprises (guarantee; collateral; subsidiary engineering tools).

10. Engineering tools for control organization at an agricultural enterprise (zero and zero specialized engineering tools).

Depending on the methods used, the model of agricultural engineering tools includes six blocks (figure 1).

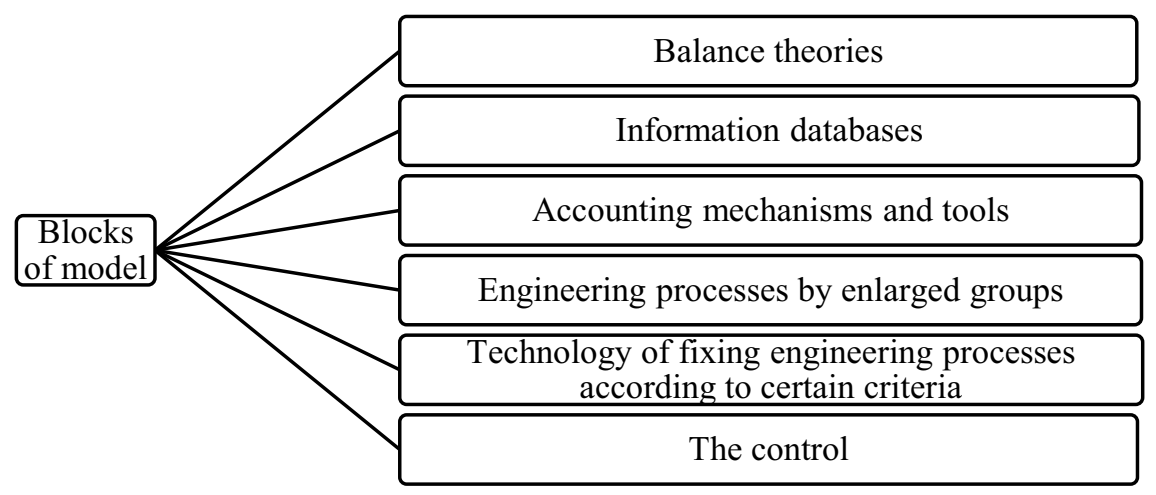

Fig. 1. Blocks of model

The first block of the model is represented by the need to apply methods of balance construction, which will enable the agricultural sector to apply balance theories such as immunization, hedged, synergistic, fractal and other ones based on an appropriate definition of net assets and liabilities, the formation of income and expenses under the conditions of 
hypothetical implementation of processes with conditionally realizable assets with the satisfaction of the obligations of an agricultural organization.

The second block of the model includes construction of digital (electronic; information) databases according to a specific architectonics in integration with an established system for fixing all the processes occurring at an agricultural enterprise. One of the most common engineering mechanisms is conduction of special surveys in order to obtain operational information.

The third block of the model is represented by accounting mechanisms and engineering tools in the context of changes with consolidation according to the corresponding objects of processes fixing taking into account various options, accounting and control indicators and with the following control system organization.

In this block it is possible to highlight such strategic engineering mechanisms as development of a strategy for an agricultural enterprise in the context of activities, formation of aggregates of the reserve system with its subsequent determination taking into account external and internal factors of influence; application of hedged engineering tools to identify alternative strategic decisions and control implementation of the developed strategic decisions. This block should include use of an engineering tools system that ensures protection efficiency of the rights belonging to the agricultural enterprise founders (correct determination of the value of the enterprise, control of key indicators during enterprise reformation; meeting property rights; determination of positive and negative aspects of the enterprise, determination of the reserve system condition; formation of a management system for various enterprise objects, development and approbation of adequate engineering tools). It is possible to ensure control indicators of founders rights protection efficiency using organic, substantial, actuarial, hedged and integrated risk engineering tools.

The fourth block of the model includes fixing engineering processes for enlarged groups of ongoing processes at an agricultural enterprise. The fixation and consolidation algorithm is a sequential process of treating the information received and obtaining the final data.

With the introduction of digitalization, the use of algorithms has expanded significantly in the field of application and use of engineering tools. Algorithmization made it possible to use dozens of the most diverse drivers for fixing ongoing processes, e.g.: cost drivers, costs, types of activities, ongoing processes, functional and costing drivers and counter service drivers. So, in its turn, the use of value drivers at agricultural enterprises makes it possible to organize value-oriented management of engineering processes for setting goals, forecasting, reporting formation, stimulating activities of the enterprise with a reference to the strategy and taking into account alternative options for strategic and tactical planning and control.

The fifth block of the model makes it possible to use the technology of fixing engineering processes according to certain criteria, where a wide variety of input data can be used depending on the engineering problems to be solved, emerging at agricultural enterprises. At the same time, the end of the engineering process will be the formation of the result in the form of engineering reports with an indication of net liabilities in the corresponding assessment.

The sixth block of the model is represented by engineering control tools, which include functional engineering tools comprising five aggregates: accounting data, data to ensure control procedures using appropriate generally accepted control methods, functional systems of derived engineering reports, property control based on indicators of engineering tools.

\section{Conclusion}


The model of agricultural engineering proposed as a result of the research carried out during the work, is designed to ensure that external and internal factors are taken into account; affecting agricultural enterprises to manage change.

This model characterizes property management, risks, backup system, innovative projects and reorganization processes, as well as human resource management; solvency, pledges and liabilities based on appropriate engineering tools. These tools are a system of computer programs contributing to the formation of a system of intelligent agriculture based on appropriate engineering technologies in order to ensure change management occurring in the agricultural sector.

\section{References}

1. A. Kuckertz, L. Brandle, A. Gaudig, S. Hinderer, C. A. M. Reyes, A. Prochotta, K. M. Steinbrink, E. S. C. Berger, Startups in times of crisis - A rapid response to the COVID-19 pandemic. Journal of Business Venturing Insights, 13, e00169 (2020) https://doi.org/10.1016/j.jbvi.2020.e00169

2. M. Nicola, Z. Alsaf, C. Sohrabi, A. Kerwan, A. Al-Jabir, C. Iosifidis, M. Agha, R. Agha, The Socio-Economic Implications of the Coronavirus and COVID-19 Pandemic: A Review. International Journal of Surgery Available online 17 April 2020 https://doi.org/10.1016/j.ijsu.2020.04.018

3. M. S. Rizwan, G. Ahmad, D. Ashraf, Systemic risk: The impact of COVID-19. Finance Research Letters; Available online 4 July 2020, 101682 (2020) https://doi.org/10.1016/j.frl.2020.101682

4. D. Zhang, M. Hu, Q. Ji, Financial markets under the global pandemic of COVID-19. Finance Research Letters Available online 16 April 2020, 101528 (2020) https://doi.org/10.1016/j.frl.2020.101528

5. R. M. Cortez, W. J. Johnston, The Coronavirus crisis in B2B settings: Crisis uniqueness and managerial implications based on social exchange theory. Industrial Marketing Management Available online 7 May $2020 \quad$ (2020) https://doi.org/10.1016/j.indmarman.2020.05.004

6. P. A. Krasnokutskiy, E. A. Ugnich, P. M. Taranov, Modern Scientific and Methodological Approaches to Assessing the Competitiveness of the Region: Application Problems. IOP Conference Series: Earth and Environmental Science, (2019) DOI: 10.1088/1755-1315/272/3/032179

7. A. V. Kolesnikov, T. I. Nasedkina, Y. U. Zdorovets, L. N. Gruzdova, A. I. Chernykh, O. V. Goncharenko, Yu. A. Kitayov, Digital technologies development in Russia Dilemas Contemporáneos: Educación; Política Y Valores Year VII; Special Edition; October 2019 (2020)

8. A. I. Pakhomova, R. A. Yalmaev, E. V. Belokurova, L. V. Shabaltina, Scenario of HiTech Growth of Innovative Economy in Modern Russia. Lecture Notes in Networks and Systems, 91, 544-551 (2020) DOI: 10.1007/978-3-030-32015-7_61

9. A. V. Bogoviz, P. M. Taranov, A. V. Shuvaev, Innovational tools for provision of food security through state support for the agro-industrial complex in the conditions of digital economy Advances in Intelligent Systems and Computing, 622, 659-665 (2018) DOI: 10.1007/978-3-319-75383-6_84

10. Z. Sai, Y. Fan, T. Yuliang, X. Lei, Z. Yifong, Optimized algorithm of sensor node deployment for intelligent agricultural monitoring. Computers and Electronics in Agriculture, 127, 76-86 (2016) https://doi.org/10.1016/j.compag.2016.06.001 
11. J. A. Gázquez, N. N. Castellano, F. Manzano-Agugliaro, Intelligent low cost telecontrol system for agricultural vehicles in harmful environments. Journal of Cleaner Production, 113, 1 February 2016, 204-215 https://doi.org/10.1016/j.jclepro.2015.11.015.

12. H. Tian, T. Wang, Y. Liu, X. Qiao, Y. Li, Computer vision technology in agricultural automation -A review. Information Processing in Agriculture, 7(1), 1-19, (2020) https://doi.org/10.1016/j.inpa.2019.09.006

13. T. Gorokhova, et al., Modern problems of the product market of Russia. E3S Web of Conferences, 164, 09034 (2020) doi: 10.1051/e3sconf/202016409034

14. A. E. Chernaya, M. N. Kabanenko, S. N. Ugrimova, Improvement of agro-industrial complex management at the federal level. IOP Conference Series: Earth and Environmental Science, 274(1) (2019) DOI: 10.1088/1755-1315/274/1/012073.

15. I. V. Terenina, D. D. Kostoglodov, L. D. Kiyanova, O. I. Usatkina, Tools to Improve the Efficiency of Import Substitution in the Agro-industrial Complex under Economic Sanctions .International Journal of Economics and Business Administration, 7, 325338 (2019) 